\title{
Investigation of inversion characteristics in atmospheric boundary layer: a case study of Tehran, Iran
}

\author{
Taghi Tavousi ${ }^{1} \cdot$ Nasrin Hussein Abadi $^{1}$
}

Received: 25 April 2016/ Accepted: 21 May 2016/Published online: 6 June 2016

(C) Springer International Publishing Switzerland 2016

\begin{abstract}
Atmospheric stability originated from temperature inversion is a main challenge in the metropolitan areas especially during the cold seasons. This study aims to investigate temperature inversion characteristics of atmospheric boundary layer in Tehran within 2010-2014. Some parameters such as height, layer thickness, air pressure and temperature difference between base and top of inversion layer were studied in order to detect radiation and subsidence inversions. The results showed that among total 1138 days with inversion events about 1015 and 123 days were classified as radiation and subsidence inversions, respectively. According to an empirical equation, daily inversion intensity was categorized from weak to severe. The most inversions occurred in summer while, the least happened in spring. However, the most severe intensity values were recorded in autumn with 58 days, while the weakest values were recorded in spring with 170 days. Height of the base level of the inversion layer in all autumn seasons is in lowest distance from Earth surface. Hence, environmental impact of the inversion events in autumn is more intense in Tehran.
\end{abstract}

Keywords Temperature profile - Inversion intensity · Atmospheric stability $\cdot$ Boundary layer $\cdot$ Tehran

Nasrin Hussein Abadi

hosseinabadyn@pgs.usb.ac.ir

Taghi Tavousi

t.tavousi@gep.usb.ac.ir

1 Department of Physical Geography and Climatology, University of Sistan and Baluchestan, Zahedan, Iran

\section{Introduction}

The temperature as a function of height above the surface is an indicator of the stability of the boundary layer (Miller et al. 2013). Temperature inversion plays an important role in determining atmospheric circulation and structure by affecting vertical motion of air mass, the consequent convective activity and rainfall (Johnson et al. 1996; Mapes and Zuidema 1996; Esteban and Chen 2008). Five processes responsible for the inversion variations includes cold-air advection accompanied by a cold-surge event, cloud-top radiative cooling, adiabatic heating due to subsidence, shallow convection at or near the observation site, and diurnal heating process due to boundary-layer growth (Ogino et al. 2010). Generally in the troposphere, the temperature decreases with increasing height in a natural manner. However, a temperature inversion is a condition where the temperature increases with height (Glickman 2000; Zhang et al. 2011). The inversion layer will influence local atmospheric thermal and dynamical structure such as restraining air vertical mixing and limiting air convection (Johnson et al. 1999; Nodzu et al. 2006). Among the tropospheric inversion layers (e.g., lower and upper tropospheric inversions), the boundary inversion layer is often observed in the atmospheric boundary layer (ABL), below $2 \mathrm{~km}$ (Busch et al. 1982), that is known surface-based inversion (SBI). SBI acts as a lid or barrier concerning near-surface and atmosphere constituent exchange (Zhang et al. 2011). Depending upon the synoptic condition, the flow above the SBI may also develop thermal inversions called elevated inversion (EI) layers (Mayfield and Fochesatto 2013). To detect the inversion layers in the ABL, radiosonde method have been widely implemented by Zhang et al. (2011), Mayfield and Fochesatto (2013) and Malingowski et al. (2014). This method depends on the application of temperature profiles 
that be extracted from upper air observation diagrams such as Skew-T. The present study aims to apply radiosonde method to investigate the inversion characteristics of the $\mathrm{ABL}$ in Tehran within 2010-2014.

\section{Methodology}

\section{Study area description}

Tehran metropolis with $800 \mathrm{~km}^{2}$ surface area is located in southern slopes of Alborz Mountains, Northern Iran. Tehran metropolitan area with altitude of 900-1900 m above sea level is coordinated between latitude $35^{\circ} 41^{\prime} 39^{\prime \prime} \mathrm{N}$ and the longitude $51^{\circ} 25^{\prime} 17^{\prime \prime} \mathrm{E}$. Dominant morphology of Tehran varies between high-elevated areas to low lands in north and south, respectively. Main climatology of Tehran is classified as semi-arid climate with mean annual temperature and annual precipitation of $17{ }^{\circ} \mathrm{C}$ and $230 \mathrm{~mm}$, respectively (Fig. 1). The topographical construction of Tehran plays an undeniable role in prevailing local winds and stable air advection in Tehran.

\section{Data and methods}

A schematic illustration of a typical inversion temperature profile is shown in Fig. 2 (Iacobellis et al. 2009). To quantify an inversion, several different measures are used, including height of the base $\left(\mathrm{Z}_{\mathrm{BASE}}\right)$ and top $\left(\mathrm{Z}_{\mathrm{TOP}}\right)$ levels of the inversion layer from Earth surface, temperature at the base $\left(\mathrm{T}_{\mathrm{BASE}}\right)$ and top $\left(\mathrm{T}_{\mathrm{TOP}}\right)$ levels of the inversion layer, temperature difference ( $\mathrm{DT}_{\mathrm{INV}}$ ) across the inversion layer and thickness of the inversion layer $\left(\mathrm{DZ}_{\mathrm{INV}}\right)$. Accurate computation of these quantities generally requires high-resolution vertical profiles of temperature. In this regard, air vertical profile data for Tehran-Mehrabad Radiosonde station (code: 40754) were gathered in diurnal, monthly, and seasonal scales within 2010-2014 taken from the University of Wyoming via: (http://weather.uwyo.edu/ upperair/sounding.html). According to temperature profiles at Skew-T diagrams, all diurnal data were examined to detect boundary layer inversion, when a temperature at a given altitude in the sounding diagram was warmer than the temperature at an altitude below it. In the case when more than one inversion is observed, the largest inversion in terms of $\mathrm{DT}_{\mathrm{INV}}$ is used. Then the extracted inversions were classified in two types of radiation and subsidence. Subsidence inversions were defined as having a base level at least $50 \mathrm{~m}$ above the surface while, radiation inversions are defined as cases when the base of the temperature inversion lies at the surface (Iacobellis et al. 2009). Hence, the temperature lapse rate across the inversion layer $\left(\mathrm{DT}_{\mathrm{INV}} / \mathrm{DZ}_{\mathrm{INV}}\right)$ is used to measure the atmospheric stability, where the rate $>0,<0$, and $=0$ represents
Fig. 1 a General position of the study area, b digital elevation model, $\mathbf{c}$ mean annual temperature, and $\mathbf{d}$ annual precipitation

Fig. 2 Schematic diagram used to characterize boundary layer temperature inversions showing some of the measures

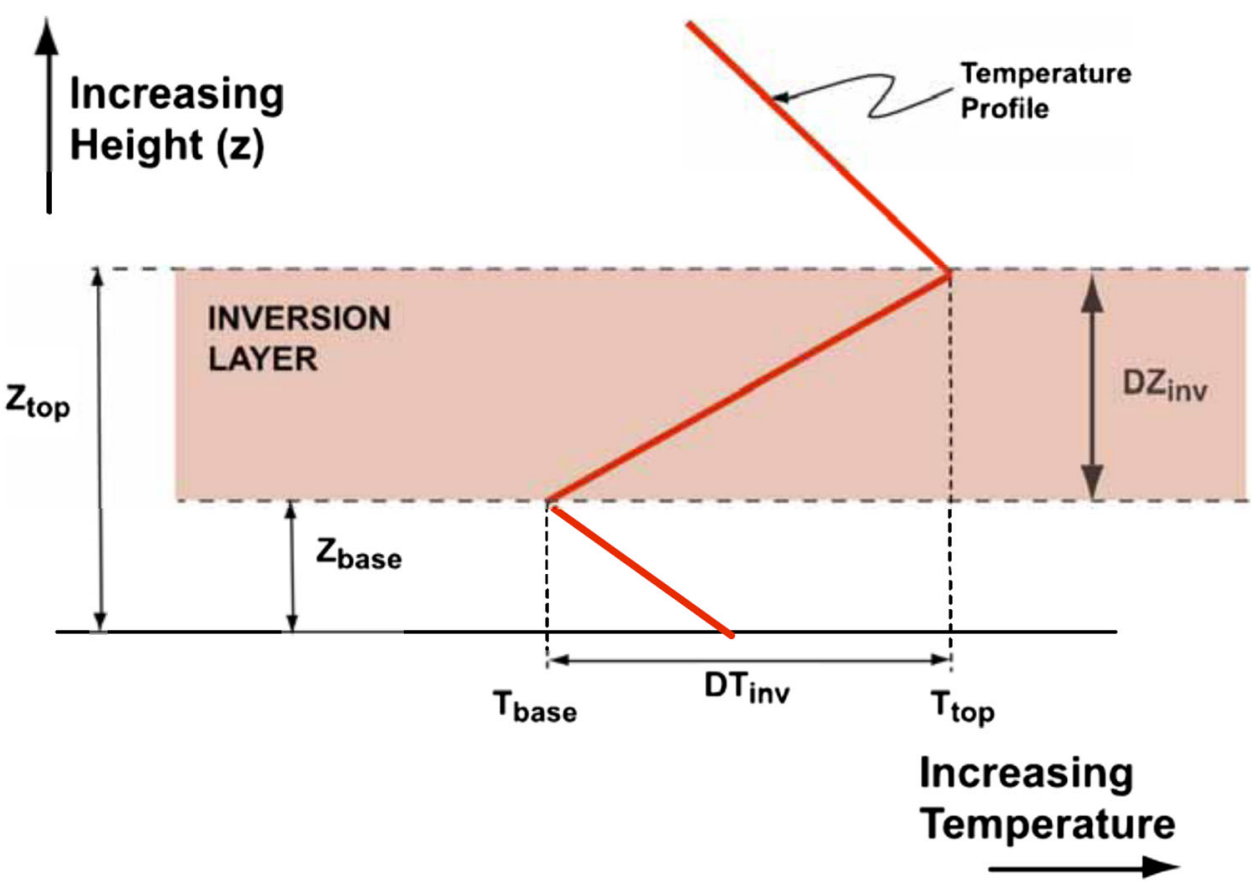

stable warm-air-advection, unstable subsidence and neutral air conditions, respectively. According to lapse rate measures, an empirical equation was employed to measure of inversion intensity as follow Equation:

$\mathrm{I}=\left(\mathrm{DT}_{\mathrm{INV}}\right)^{2} / 3+\mathrm{Z}(\mathrm{DZ} \mathrm{INV})$

where $\mathrm{DT}_{\mathrm{INV}}$ is temperature difference across inversion layer in Kelvin and $\mathrm{DZ}_{\mathrm{INV}}$ is the thickness of inversion layer in meter and $\mathrm{Z}$ is station altitude in hectometer.

\section{Results and discussion}

According to temperature profiles at Skew-T diagrams, all diurnal data were examined to detect boundary layer inversions and then were classified in two types of radiation and subsidence. In this regard, daily frequency of radiation and subsidence inversions within 2010-2014 was produced in Table 1. According to this table, the most inversions occurred in 2014 by 280 days and the lowest number of inversions happened in 2012 by 202 days. In this time-period, radiation inversions $(\sim 90 \%)$ have been recorded more than subsidence inversions $(\sim 10 \%)$. Generally, the base and top levels of inversions have been recorded at the mean height of 1209 and $1341 \mathrm{~m}$, respectively. The average thickness of inversion has been estimated about $132 \mathrm{~m}$ within 2010-2014. To detect seasonal variations of inversion occurrences, all inversions were distributed in Table 2. On this basis, the most inversions occurred in all summers by 336 days ( $30 \%)$ and the lowest number of inversions happened in all winters by
244 days $(\sim 20 \%)$. Therefore, the most radiation and subsidence inversions occurred in all summers. The highest and lowest values of inversion thickness have been estimated for summer and autumn seasons as 148 and $117 \mathrm{~m}$, respectively. In this regard, height of the base ( $\left.Z_{B A S E}\right)$ level of the inversion layer in all autumn seasons is in lowest distance from Earth surface. Hence, environmental impact of the inversion events in autumn is more intense in Tehran. To detect monthly variations of inversion occurrences, all inversions were distributed in Table 3. On this basis, the most inversions occurred in August by 122 days $(\sim 10 \%)$ and the lowest number of inversions happened in February by 63 days $(\sim 5 \%)$. Therefore, the most radiation and subsidence inversions occurred in all summer months from June to August. Height of the base $\left(\mathrm{Z}_{\mathrm{BASE}}\right)$ level of the inversion layer in November is in lowest distance from Earth surface. November is the susceptible month to enhance of air pollution in Tehran metropolitan region. All of the inversion types in November is categorized as radiation inversion not subsidence one. While, temperature inversions dominantly were observed as anticyclone subsidence type in summer months. To detect temperature characteristics of the inversions within 2010-2014, monthly temperature difference ( $\mathrm{DT}_{\mathrm{INV}}$ ) values across the inversion layer were calculated in Table 4 . The table revealed the minimum and maximum values of mean temperature at the base $\left(\mathrm{T}_{\mathrm{BASE}}\right)$ level of the inversion layer as 3.8 and $27.5^{\circ} \mathrm{C}$ in January and July, respectively. So, the table revealed the minimum and maximum values of mean temperature at the top $\left(\mathrm{T}_{\mathrm{TOP}}\right)$ level of the inversion layer as 5.4 and $30^{\circ} \mathrm{C}$ in January and July, respectively. Minimum and maximum 
Table 1 Annual characteristics of inversion in Tehran (2010-2014)
Table 2 Seasonal characteristics of inversion in Tehran (2010-2014)

\begin{tabular}{lcccccc}
\hline Year & \multicolumn{2}{l}{ Inversion frequency (day) } & & $Z_{\text {BASE }}(\mathrm{m})$ & $Z_{\text {TOP }}(\mathrm{m})$ & Thickness (m) \\
\cline { 2 - 4 } & Total & Radiation & Subsidence & & & \\
\hline 2010 & 204 & 187 & 17 & 1201 & 1333 & 133 \\
2011 & 211 & 185 & 26 & 1213 & 1359 & 146 \\
2012 & 202 & 191 & 11 & 1202 & 1347 & 145 \\
2013 & 241 & 197 & 44 & 1222 & 1350 & 128 \\
2014 & 280 & 255 & 25 & 1210 & 1319 & 109 \\
Sum & 1138 & 1015 & 123 & - & - & - \\
Mean & 227 & 203 & 24 & 1209 & 1341 & 132 \\
\hline
\end{tabular}

\begin{tabular}{|c|c|c|c|c|c|c|}
\hline \multirow[t]{2}{*}{ Season } & \multicolumn{3}{|c|}{ Inversion frequency (day) } & \multirow[t]{2}{*}{$\mathrm{Z}_{\mathrm{BASE}}(\mathrm{m})$} & \multirow[t]{2}{*}{$\mathrm{Z}_{\mathrm{TOP}}(\mathrm{m})$} & \multirow[t]{2}{*}{ Thickness (m) } \\
\hline & Total & Radiation & Subsidence & & & \\
\hline Winter & 244 & 225 & 19 & 1211 & 1339 & 128 \\
\hline Spring & 284 & 247 & 37 & 1217 & 1353 & 137 \\
\hline Summer & 336 & 275 & 61 & 1215 & 1363 & 148 \\
\hline Autumn & 274 & 268 & 6 & 1194 & 1311 & 117 \\
\hline Sum & 1138 & 1015 & 123 & - & - & - \\
\hline Mean & - & - & - & 1209 & 1341 & 132 \\
\hline
\end{tabular}

Table 3 Monthly

characteristics of inversion in Tehran (2010-2014)

\begin{tabular}{lllllll}
\hline Month & \multicolumn{2}{l}{ Inversion frequency (day) } & & $Z_{\text {BASE }}(\mathrm{m})$ & $Z_{\text {TOP }}(\mathrm{m})$ & Thickness $(\mathrm{m})$ \\
\cline { 2 - 4 } & Total & Radiation & Subsidence & & & \\
\hline Jan & 82 & 74 & 8 & 1216 & 1333 & 117 \\
Feb & 63 & 55 & 8 & 1222 & 1327 & 105 \\
Mar & 92 & 82 & 10 & 1217 & 1352 & 135 \\
Apr & 96 & 84 & 12 & 1215 & 1352 & 137 \\
May & 96 & 81 & 15 & 1218 & 1357 & 139 \\
Jun & 101 & 81 & 20 & 1218 & 1378 & 160 \\
Jul & 113 & 87 & 26 & 1219 & 1367 & 148 \\
Aug & 122 & 107 & 15 & 1207 & 1348 & 140 \\
Sep & 97 & 97 & 0 & 1192 & 1317 & 125 \\
Oct & 88 & 82 & 6 & 1198 & 1333 & 135 \\
Nov & 89 & 89 & 0 & 1191 & 1283 & 92 \\
Dec & 99 & 96 & 3 & 1198 & 1350 & 152 \\
Sum & 1138 & 1015 & 123 & - & - & - \\
Mean & - & - & - & 1209 & 1341 & 132 \\
\hline
\end{tabular}

values of temperature difference (DT $\mathrm{DTV}_{\mathrm{INV}}$ ) across the inversion layer were estimated in Mars/April and November/December as $\sim 1.5$ and $\sim 3.0{ }^{\circ} \mathrm{C}$, respectively. Then, the higher $\mathrm{DT}_{\mathrm{INV}}$ values were extracted dominantly for inversions in autumn months that depend on strong inversion while, the lower values were observed dominantly for inversions in spring months that depend on weak inversion. According to the temperature lapse rate across the inversion layer $\left(\mathrm{DT}_{\mathrm{INV}} / \mathrm{DZ}_{\mathrm{INV}}\right)$, the stable and unstable types of total inversions were recorded as $696(\sim 60 \%)$ and 431 $(\sim 39 \%)$ days, respectively. About $1 \%$ of inversion events were classified as neutral condition (Table 5). On this basis, atmospheric stable condition results in the most inversion events in all summer and autumn seasons. To classify the intensity of inversions, all inversions were categorized as weak, moderate, strong and severe inversion based on Eq. 1 (Table 6). The results revealed that about $55,25,5$ and $10 \%$ of total inversions could be categorized as weak, moderate, strong and severe intensity values. The most severe intensity values were recorded in autumn with 58 days, while the weakest values were recorded in spring with 170 days. 
Table 4 Monthly temperature characteristics of inversion in Tehran (2010-2014)

\begin{tabular}{|c|c|c|c|c|c|c|c|c|c|c|c|c|c|}
\hline \multirow[t]{2}{*}{ Year } & \multirow[t]{2}{*}{ Character $\left({ }^{\circ} \mathrm{C}\right)$} & \multicolumn{12}{|c|}{ Inversion frequency (day) } \\
\hline & & Jan & Feb & Mar & Apr & May & Jun & Jul & Aug & Sep & Oct & Nov & Dec \\
\hline \multirow[t]{3}{*}{2010} & $\mathrm{~T}_{\mathrm{BASE}}$ & 6.8 & 6.1 & 12.8 & 14.3 & 18.9 & 25.2 & 26.4 & 18.8 & 9.5 & 7.1 & 9.4 & 7.1 \\
\hline & $\mathrm{T}_{\mathrm{TOP}}$ & 8.3 & 7.8 & 15.8 & 16.5 & 20.9 & 27.6 & 29 & 21.8 & 12.7 & 9.3 & 12.6 & 9.3 \\
\hline & $\mathrm{DT}_{\mathrm{INV}}$ & 1.5 & 1.7 & 3 & 2.2 & 2 & 2.4 & 2.6 & 3 & 3.2 & 2.2 & 3.2 & 2.2 \\
\hline \multirow[t]{3}{*}{2011} & $\mathrm{~T}_{\mathrm{BASE}}$ & 3.3 & 3.4 & 8.2 & 15.7 & 20.4 & 21.7 & 29.2 & 27.3 & 22.6 & 14.9 & 6.6 & 2.9 \\
\hline & $\mathrm{T}_{\mathrm{TOP}}$ & 4.4 & 5.2 & 9.6 & 17.2 & 22.2 & 23.4 & 31 & 29.8 & 24.9 & 17 & 7.9 & 4.6 \\
\hline & $\mathrm{DT}_{\mathrm{INV}}$ & 1.1 & 1.8 & 1.4 & 1.5 & 1.8 & 1.7 & 1.8 & 2.5 & 2.3 & 2.1 & 1.3 & 1.7 \\
\hline \multirow[t]{3}{*}{2012} & $\mathrm{~T}_{\mathrm{BASE}}$ & 2.1 & 2.4 & 7.7 & 15.2 & 16.4 & 23.1 & 27.6 & 28.1 & 24.4 & 19 & 12.1 & 4.4 \\
\hline & $\mathrm{T}_{\mathrm{TOP}}$ & 3.5 & 4.4 & 9.3 & 16.8 & 20.1 & 25.1 & 29.8 & 30.1 & 26.1 & 20.7 & 13.5 & 5.8 \\
\hline & $\mathrm{DT}_{\mathrm{INV}}$ & 1.4 & 2 & 1.6 & 1.6 & 3.7 & 2 & 2.2 & 2 & 1.7 & 1.7 & 1.4 & 1.4 \\
\hline \multirow[t]{3}{*}{2013} & $\mathrm{~T}_{\mathrm{BASE}}$ & 4.1 & 6.8 & 14.7 & 16.3 & 18.1 & 22.8 & 26.6 & 25.3 & 25.2 & 15.8 & 11.8 & 3.9 \\
\hline & $\mathrm{T}_{\mathrm{TOP}}$ & 6.4 & 8.3 & 15.8 & 17.3 & 20.1 & 26.4 & 30.1 & 27.9 & 27.1 & 18.2 & 13 & 5.6 \\
\hline & $\mathrm{DT}_{\mathrm{INV}}$ & 2.3 & 1.5 & 1.1 & 1 & 2 & 3.6 & 3.5 & 2.6 & 1.9 & 2.4 & 1.2 & 1.7 \\
\hline \multirow[t]{3}{*}{2014} & $\mathrm{~T}_{\text {BASE }}$ & 2.8 & 4.8 & 9.5 & 14.5 & 21.9 & 25.5 & 27.5 & 28 & 23 & 16.9 & 9.5 & 6.9 \\
\hline & $\mathrm{T}_{\mathrm{TOP}}$ & 4.4 & 6.4 & 10.3 & 15.9 & 23.2 & 27.4 & 30.3 & 31 & 27 & 21.1 & 17.3 & 16.1 \\
\hline & $\mathrm{DT}_{\mathrm{INV}}$ & 1.6 & 1.6 & 0.8 & 1.4 & 1.3 & 1.9 & 2.8 & 3 & 4 & 4.2 & 7.8 & 9.2 \\
\hline \multirow[t]{3}{*}{ Mean } & $\mathrm{T}_{\mathrm{BASE}}$ & 3.8 & 4.7 & 10.6 & 15.2 & 19.1 & 23.7 & 27.5 & 25.5 & 20.9 & 14.7 & 9.9 & 5 \\
\hline & $\mathrm{T}_{\mathrm{TOP}}$ & 5.4 & 6.4 & 12.2 & 16.7 & 21.3 & 26 & 30 & 28.1 & 23.6 & 17.3 & 12.9 & 8.3 \\
\hline & $\mathrm{DT}_{\mathrm{INV}}$ & 1.6 & 1.7 & 1.6 & 1.5 & 2.2 & 2.3 & 2.6 & 2.6 & 2.6 & 2.5 & 3 & 3.2 \\
\hline
\end{tabular}

Table 5 Classification of seasonal inversion events based on temperature lapse rate

\begin{tabular}{llrrrrr}
\hline \multirow{2}{*}{ Lapse rate } & Stability & \multicolumn{5}{l}{ Inversion frequency (day) } \\
\cline { 3 - 7 } & & Winter & Spring & Summer & Autumn & Total \\
\hline$>0$ & Stable & 151 & 140 & 233 & 172 & 696 \\
$<0$ & Unstable & 91 & 142 & 102 & 96 & 431 \\
$=0$ & Neutral & 2 & 2 & 1 & 6 & 11 \\
- & Total & 244 & 284 & 336 & 274 & 1138 \\
\hline
\end{tabular}

Table 6 Classification of seasonal inversion events based on intensity equation

\begin{tabular}{llrrrrr}
\hline I & Intensity & \multicolumn{6}{c}{ Inversion frequency (day) } & \\
\cline { 3 - 7 } & & Winter & Winter & Summer & Autumn & Total \\
\hline $.00-.01$ & Weak & 160 & 160 & 165 & 160 & 655 \\
$.01-.02$ & Moderate & 50 & 50 & 115 & 43 & 298 \\
$.02-.03$ & Strong & 12 & 12 & 29 & 13 & 68 \\
$>.03$ & Severe & 22 & 22 & 27 & 58 & 117 \\
- & Total & 244 & 244 & 336 & 274 & 1138 \\
\hline
\end{tabular}

\section{Conclusion}

The results showed that about 227 days could be observed as mean annual temperature inversions within 2010-2014. In this regard, radiation inversions $(\sim 90 \%)$ have been recorded more than subsidence inversions $(\sim 10 \%)$. The most inversions occurred in all summers by 336 days
( $\sim 30 \%)$ and the lowest number of inversions happened in all winters by 244 days $(\sim 20 \%)$. Therefore, temperature inversions dominantly were observed as anticyclone subsidence type in summer months. This is mainly associated with atmospheric stability as a result of the presence of subtropical high pressure system in warm period with subsidence in upper air. The highest and lowest values of inversion thickness have been estimated for summer and autumn seasons as 148 and $117 \mathrm{~m}$, respectively. This relates to increased and dropped temperature in summer and autumn, respectively. The most severe intensity values were recorded in autumn with 58 days, while the weakest values were recorded in spring with 170 days. Furthermore, height of the base level of the inversion layer in autumn is in lowest distance from Earth surface. Hence, autumn is the susceptible season to enhance of air pollution in Tehran metropolitan region.

Acknowledgements We are grateful to Dr. Mohammad Reza Mansouri Daneshvar from Department of Geography and Natural Hazards at Research Institute of Shakhes Pajouh in Isfahan, Iran, for his superior advises and professional suggestions.

\section{References}

Busch N, Ebel U, Kraus H, Schaller E (1982) The structure of the sub polar inversion-capped ABL. Arch Meteor Geophy 331:1-18

Esteban MA, Chen YL (2008) The impact of trade wind strength on precipitation over the windward side of the Island of Hawaii. Mon Weather Rev 136:913-928 
Glickman T (2000) Glossary of meteorology, 2nd edition. American Meteorological Society, p 855

Iacobellis SF, Norris JR, Kanamitsu M, Tyree M, Cayan DC (2009) Climate variability and California low-level temperature inversions. California Climate Change Center, p 48

Johnson RH, Ciesielski PE, Hart KA (1996) Tropical inversions near the $0^{\circ} \mathrm{C}$ level. J Atmos Sci 53:1838-1855

Johnson RH, Rickenbach TM, Rutledge SA, Ciesielski PE, Schubert WH (1999) Trimodal characteristics of tropical convection. J Clim 12:2397-2418

Malingowski J, Atkinson D, Fochesatto J, Cherry J, Stevens E (2014) An observational study of radiation temperature inversions in Fairbanks, Alaska. Polar Sci 8:24-39

Mapes BE, Zuidema P (1996) Radiative-dynamical consequences of dry tongues in the tropical troposphere. J Atmos Sci 53:620-638

Mayfield J, Fochesatto GJ (2013) The layered structure of the winter atmospheric boundary layer in the interior of Alaska. J Applied Meteorol Climatol 52:953-973
Miller NB, Turner DD, Bennartz R, Shupe MD, Kulie MS, Cadeddu MP, Walden VP (2013) Surface-based inversions above central Greenland. J Geophys Res Atmos 118:495-506

Nodzu MI, Ogino SY, Tachibana Y, Yamanaka MD (2006) Climatological description of seasonal variations in lower tropospheric temperature inversion layers over the Indochina Peninsula. J Clim 19:3307-3319

Ogino SY, Nodzu MI, Tachibana Y, Matsumoto J (2010) Temperature inversions over the Inland Indochina revealed by GAME-T enhanced rawinsonde observations. SOLA 6:5-8

Zhang YH, Zhang SD, Yi F, Chen ZY (2011) Statistics of lower tropospheric inversions over the continental United States. Ann Geophys 29:401-410 